\title{
A prospective study on the assessment of level of depression, anxiety and stress among teaching faculties of a Nursing college
}

\author{
Morteza Alibakhshi Kenari \\ Martyr Beheshti University of Medical Sciences and Health Services, Tehran, Iran \\ Email address: \\ Morteza.Alibakhshikenari@gmail.com
}

\section{To cite this article:}

Morteza Alibakhshi Kenari. A Prospective Study on the Assessment of Level of Depression, Anxiety and Stress Among Teaching Faculties of a Nursing College. American Journal of Nursing Science. Vol. 3, No. 4, 2014, pp. 43-47. doi: 10.11648/j.ajns.20140304.11

\begin{abstract}
Aim: Psychological stability is indeed an important predictor that could contribute to high academic achievement. Depression, stress, and anxiety are among the psychological problems that are common among teachers and students. The study was aimed to assess the level of depression, anxiety and stress among the teaching faculties. Study design: It is a questionnaire based prospective observational study. Place and Duration of the study: The study was carried out at a Nursing college for a period of 3 months. Methodology: Depression, Anxiety and Stress score scale (DASS-21) questionnaire was used in the study to assess the parameters. Conclusion: The combined assessment on level of depression, anxiety and stress revealed that 16 percent of the teaching faculties were observed with anxiety alone and 16 percent with Depression with Anxiety. Twelve percent of the faculties were found to have all the three conditions. It indicates that nearly 44 percent of the faculties were found to have some level of mind strife, so this should be annulled in all the aspects to give more academic output and sound health. Dealing with issues surrounding workload, student behaviour, and employment conditions, may help reduce stress, and thus reduce depression and anxiety among teachers.
\end{abstract}

Keywords: Depression, Anxiety, Stress, Mood Changes, Behavior

\section{Introduction}

Performance in academic life demands all aspects of well-being, those that includes, social, physical, spiritual, psychological and emotional wellbeing. Those who are experiencing psychological problems like depression, anxiety and stress, may possibly face problems in managing their academic performance. Psychological stability is indeed an important predictor that could contribute to high academic achievement. Hence, it is very much crucial to review and examine the psychological well-being of the individual. Depression, stress, and anxiety are among the psychological problems that are common among teachers and students. These three conditions are interrelated each other [1].

\subsection{Depression}

A depressed mood is the experience of unhappiness or sorrow. Depression may involve feelings of being weak, hopeless, helpless, sad, disappointed, despairing, and frustrated. The depressed individual may unable to perform sound in academic life due the less courage in what they are doing. They may feel that 31 they are not reaching the standard of performance set for them. As a result they continuously feel disappointed and despairing. They observe things negatively and reflect themselves as failures. This condition can certainly contribute too many staid problems in their academic life such as poor grades.

\subsection{Anxiety}

Anxiety is a psychological disorder that is associated with significant suffering and impairment of functioning. It has a blend of thoughts and feelings, characterised by a sense of uncontrollability and unpredictability over potentially adverse life events. Individuals with anxiety may have apprehensions that frequently interfere with everyday life performance and academic situations. Generally, anxiety may produce negative effect on 
individual's performance. Individuals with high level of anxiety may perform less than without anxiety individuals. It is imperative to consider aptitudes, motives, cognitive assessments and past experience when analysing the anxiety and examining how it related to the performance.

\subsection{Stress}

Stress is a mechanism of any internal or external demand made upon the body. Stress is considered as a state of individuals that result from their interaction with the environment that is perceived as too demanding and a threat to their well-being. The stressors are not only physical, but may also involve emotions. Stress was found to be a part of academicians' life and could give impact on how they cope with the demands of academic life.

However, when education is perceived as a threat, stress can elicit feelings of hopelessness and a foreboding sense of loss, thus leading to lower academic achievement.

Research shows that there exists a relationship between stressful life events and poor academic performance among academicians and there is a connection between health56 related quality of life and stress. Stress may adversely affects the physical and psychological health, and it is the most common health issue impacting their academic achievements. Heightened levels of stress had significantly more physical health problems and less satisfaction towards academic achievement compared to those reporting lower levels of stress [2]. Main objective of this current prospective study was to identify the level of Depression, Anxiety and Stress (DAS) among the teaching faculties of the nursing college.

\section{Methodology}

\subsection{Study Site}

The study was carried out at a private well reputed nursing College conducting B.Pharm., M.Pharm., Pharm.D and Pharm.D Post Baccalaureate courses with a student population of around 500 with the regular faculties of 29.

\subsection{Design of the Study}

A questionnaire based prospective observational study and carried out for a period of three months.

\subsection{Inclusion/Exclusion Criteria}

All the teaching faculties who were willing to participate in the study are included. Teaching faculties who were not interested are excluded from the study.

\subsection{Data Entry Format with DASS-21 (Depression, Anxiety and Stress Score) Questionnaire}

A separate data entry format along with DASS-21 questionnaire was prepared for the proposed study. The Depression Anxiety and Stress Scales questionnaire (DASS) consists of three different, subscales with 14 items such as
DASS-depression, anxiety, and stress [3].

\subsection{Data Collection and Analysis}

The data entry form along with DASS-21 questionnaire was distributed to the teaching faculties of our nursing college, required time was given to fill up the form and finally it was collected from the faculties. The collected data were analyzed 84 for its appropriateness and the suitability. Interpretations were made for the collected data. From the data analysis, results were obtained and conclusion was drawn.

\section{Results}

\subsection{Sex Distribution}

In our prospective study, we approached all the teachers $(n=29)$ which include 24 male and 05 female, from this 22 (88\%) male and $03(12 \%)$ female teachers responded with the response rate of 91.66 and 60 percent respectively. In this study, most of the participant were male, this may be due to fact that more than 80 percent of the teachers were male.

\subsection{Age Distribution}

The age group classification of the respondents revealed that none of respondents were below the age of 20 years. Four male $(16 \%)$ respondents were observed in the age group between 21 and 30 years, $10(40 \%)$ male and $3(12 \%)$ female were observed in the age group between 31 and 40 years. Eight (32\%) respondents were note in the age group between 41 and 50 years and none of the respondent was noted above age of 50 years.

\subsection{Academic Qualification of Teaching Faculties}

The academic qualification of the respondents were studied extensively and revealed that only one (4\%) male teacher was noted with Under-graduation qualification, 14 $(56 \%)$ male and $3(12 \%)$ female teachers were found with Post-graduation qualification. Seven (28\%) male teachers were found to have Doctor of Philosophy qualification.

\subsection{Social History of Teaching Faculties}

The social history of the study participants revealed that most of our respondents found to have both smoke and drink alcohol, it was around $52(\mathrm{n}=13)$ percent. Twenty four percent $(n=6)$ respondents drink alcohol and 24 percent $(n=6)$ found to have no social history.

\subsection{Past Medical History of Teaching Faculties}

Past medial history of the study participants revealed that 6 (24\%) participants were observed with Upper Respiratory Tract Infections, 4 (16\%) participants each were noted with Alopacia, Piles/malena and Tonsilitis/Throat Infection. Three (12\%) participants were observed with Diabetes Mellitus, 2 $(8 \%)$ participants each were noted with lower respiratory 
tract infections, Atherosclerosis, Urinary Cystitis, Peptic Ulcer and Eczeme/ Psoriasis/ Skin allergy. One (4\%) patient each was noted with Hypothyroidism with Poly Cystic Ovary Disease, Low Blood Pressure and Hypertension.

\subsection{Current Salary per Month for Teaching Faculties}

The current salary of the teachers per month was calculated in Indian rupees and it revealed that $2(8 \%)$ teachers received salary less than 10,000 INR per month, 1 (4\%) received salary between the range of 10,001 and 15,000 INR, $1(4 \%)$ being paid with a salary between the range of 15,001 and 20,000 INR and $1(4 \%)$ being paid in the range between 20,001 and 25,000 INR. Six (24\%) of the teachers received salary between the range of 25,001 and 30,000 INR, and $5(20 \%)$ were receiving salary between 30,001 and 35,000 INR. Two (8\%) teachers were receiving salary between 35,001 and 40,000 INR, only one (4\%) teacher was observed in the salary between 40,001 and 45,000 INR. Two $(8 \%)$ teachers were found to receive a salary in the range between 45,001 and 50,000 INR and only $4(16 \%)$ teachers were receiving a salary more than 50,000 INR per month.

\subsection{Family 136 History of Teaching Faculties}

The study on family history of the teachers revealed that $16(64 \%)$ of 25 teachers having children, $6(24 \%)$ teachers were unmarried and 3 (12) teachers were found to have NO children during our study period.

\subsection{Assessment of Level of Depression in Teaching Faculties}

The study on level of depression among the teaching faculties was carried out with DASS-21 questionnaire, and according to the participants score it was further categorized as Normal when the score is between 0 and 4, Mild when it is between 5 and 6 , moderate when it is between 7 and 10 . The level of depression is Severe when the score is between 11 and 13 and it is Extreme severe when the score is above 14. This level of depression assessment reveled that most of our participants are normal and 20 percent of the participants are in mild depression, 4 percent each were in moderate and severe depression. None of the participants was observed with extremely severe depression (table 1).

Table 1. Level of depression in teaching faculties

\begin{tabular}{llll}
\hline Level of Depression & Score & Number & Percentage \\
\hline Normal & $0-4$ & 18 & 72 \\
Mild & $5-6$ & 5 & 20 \\
Moderate & $7-10$ & 1 & 4 \\
Severe & $11-13$ & 1 & 4 \\
Extreme Severe & $14+$ & 00 & 0 \\
Total & & 25 & 100 \\
\hline
\end{tabular}

3.9. Assessment of level of Anxiety in Teaching Faculties

The level of anxiety among the teaching faculties was carried out in our study with DASS-2 questionnaire, and as per the participants score it was classified as Normal when they scored between 0 and 3, Mild when it is between 4 and 5 , Moderate when the score is between 6 and 7. It is further classified as severe anxiety when the score is between 8 and 9, and it is Extreme severe when the score is above 10. This level of anxiety assessment reveled that more than 50 percent $(56 \%)$ of our participants are normal and 12 percent of the participants are in mild anxiety, 8 percent each were in moderate and severe anxiety. Sixteen percent of the participants was observed with extremely severe anxiety (table 2).

Table 2. Level of anxiety in teaching faculties

\begin{tabular}{llll}
\hline Level of Anxiety & Score & Number & Percentage \\
\hline Normal & $0-3$ & 14 & 56 \\
Mild & $4-5$ & 3 & 12 \\
Moderate & $6-7$ & 2 & 8 \\
Severe & $8-9$ & 2 & 8 \\
Extreme severe & $10+$ & 4 & 16 \\
Total & & 25 & 100 \\
\hline
\end{tabular}

\subsection{Assessment of level of stress in Teaching Faculties}

The stress level among the teaching faculties was carried out with DASS-21 questionnaire, and as per the participants score it was categorized as Normal when they scored between 0 and 7, Mild when they scored between 8 and 9, Moderate when the score is between 10 and 12. It is further classified as severe stress if they scored between 13 and 16 , and it is

Extreme stress when the score is above 17. The stress assessment revealed that 92 percent of our participants are normal and 8 percent of the participants are in moderate stress. Non of our study participants were noted with mild, severe and extremely severe stress (table 3).

Table 3. Level of stress in teaching faculties

\begin{tabular}{llll}
\hline Level of Stress & Score & Number & Percentage \\
\hline Normal & $0-7$ & 23 & 92 \\
Mild & $8-9$ & 0 & 0 \\
Moderate & $10-12$ & 2 & 08 \\
Severe & $13-16$ & 0 & 0 \\
Extreme severe & $17+$ & 0 & 0 \\
Total & & 25 & 100 \\
\hline
\end{tabular}

\subsection{Combined Assessment of Depression, 190 Anxiety, Stress in Teaching Faculties}

The combined assessment on level of depression, anxiety and stress revealed that 16 percent of the teaching faculties were observed with Anxiety alone and 16 percent with Depression + Anxiety. Twelve percent of the faculties were found to have all the three conditions i.e. Depression, Anxiety and Stress. Fifty six percent of the faculties were found to have none of this condition (table 4). 
Table 4. Combined assessment of depression, anxiety, stress in teaching faculties

\begin{tabular}{lll}
\hline Status & Number & Percentage \\
\hline Depression alone & 00 & 00 \\
Anxiety alone & 04 & 16 \\
Stress alone & 00 & 00 \\
Depression + Anxiety & 04 & 16 \\
Depression + Stress & 00 & 00 \\
Anxiety + Stress & 00 & 00 \\
All & 03 & 12 \\
None & 14 & 56 \\
Total & 25 & 100 \\
\hline
\end{tabular}

\section{Discussion}

In our study, we approached all the teachers $(n=29)$ which include 24 male and 05 female, from this 22 male and 03 female teachers responded with the response rate of 91.66 and 6 percent respectively. The remaining percentage teachers were not available or they were not ready to fill the DASS-21 questionnaire due to its nature of revealing the mental ability or condition. In this study, most of the participant were male it was around 88 percent $(n=22)$ followed $b$ female 12 percent $(n=03)$. This may be due to fact that more than 80 percent of the teachers were male and only few female staffs in our study site. The age group classification of the respondents revealed that none of respondents were below the age of 20 years, this is the fact that the requirement of post -graduation qualification to teach the students of nursing college and they can complete the post 215 graduation degree only on or after the age of 23 years. A total of 13 faculties which includes 10 male and 3 female were observed in the age group between 31 and 40 years, they were conducting or taking classes for all the above mentioned courses with the minimum teaching experiences of 5 years. Eight respondents were noted in the age group between 41 and 50 years, they were having a minimum teaching experiences of 10 years and none of the respondent was noted above age of 50 years. The academic qualification of the respondents were studied extensively and revealed that only one male teacher was noted with under- graduation qualification, 14 male and 3 female teachers 222 were found with Post-graduation qualification. Seven of the teachers were found to have Doctor of Philosophy qualification.

All our study participants were noted with at-least one health complications, majority of them were found with Upper and lower Respiratory Tract Infections, this may be due to the smoking habits. Alopecia was commonly noted in our study population, this may be due to the stress and pressure over the faculties to complete the academic task. The poor quality of chalk and contaminated drinking water may be the reason for getting throat infection and tonsillitis in our study population. Atherosclerosis, Diabetes and urinary cystitis were also noted in our study, this may be due to the social history and food habit of the study population.

Only few of our study participants were receiving decent salary for their academic contribution but that also not in a level to appreciate their contribution. The current salary of the teachers per month was calculated in Indian rupees and it revealed that 2 teachers received salary less than 10,000 INR per month, 1 received salary between the range of 10,001 and 15,000 INR, 1 getting salary between the range of 15,001 and 20,000 INR and 1 in getting in the range between 20,001 and 25,000 INR. Six of the teachers received salary between the range of 25,001 and 30,000 INR, and 5 were receiving salary between 30,001 and 35,000 INR. Two teachers were receiving salary between 35,001 and 40,000 INR, only one teacher was noted in receiving a salary in the range of 40,001 and 45,000 INR. Two teachers were found to receive a salary in the range between 45,001 and 50,000 INR and only 4 teachers were receiving a salary more than 50,000 INR per month. The low salary and more work load pressure over the teaching faculties may be the reason for them to have many health and mental related illness [4].

The study on family history of the teachers revealed that 16 of 25 teachers having children, 6 teachers were unmarried and 3 teachers were found to have NO children in our study period. The lack or absence of children may create a pressure over the academic staffs within the family may leads to poor achievement in their academic target and may create some level of mental pressure or stress.

In our study, we used the DASS-21 questionnaire to analyze the level of depression, anxiety and stress among the teaching faculties. The level of depression assessment revealed that, a total of 28 percent participants are having depression, in that 20 percent are in mild depression, 4 percent each were in moderate and severe depression. This clearly indicates that nearly one third of the faculties are having depressed mind and may be due to the fact that poor working atmosphere, work load and pressure to complete their academic tasks, etc [5].

The level of anxiety among the teaching faculties was studied extensively and it revealed that nearly half of the study participants (44\%) were having anxiety, in that 16 percent of the participants was observed with extremely severe anxiety, 12 percent with mild anxiety, 8 percent each were in moderate and severe anxiety. This may due to fact that they were in un-favorable atmosphere and were in pressurized situation, again it warren the faculties to give more importance to reduce the factors that triggering anxiety [6,7].

The assessment of stress level among the teaching faculties was carried out with DASS-21 questionnaire, and it revealed that 8 percent of the participants are in moderate stress. Non of our study participants were noted with mild, severe and extremely severe stress. Ninety two percent of our participants were normal and do not have any stress during the study period.

The combined assessment on level of depression, anxiety 
and stress revealed that 16 percent of the teaching faculties were observed with anxiety alone and 16 percent with Depression + Anxiety. Twelve percent of the faculties were found to have all the three conditions i.e. Depression, Anxiety and Stress. It indicates that nearly 44 percent of the faculties were found to have some level of mind disturbances, so this should be nullified with all possible ways to give more academic output and sound health [8-10].

\section{Conclusion}

The study conclude that the organization should give immense importance to monitor the teaching faculties and to reduce the factors triggering all this depression, anxiety and stress.

The physically and mentally sound faculty is a valuable asset for each and ever organization, so they should be encouraged with good working atmosphere, comfortable work load, good and decent per capita income, motivational programs, and other possible events to do more better in the future.

\section{References}

[1] Aris S, Yasin and Mariam AD. Differences in depression, anxiety and stress between low-and high-achieving students. J. Sustain. Sci. Manage. 2011;6(1):169-178.

[2] Thomas JH. Anxiety and anxiety disorders in children: information for Parents. S5-1-4. Available from: http://www.nasponline.org/resources/intonline/anxiety_hube rty.pdf

[3] Luke P, James H, David W, Leonardo OPC, Kathryn MR, Benedict MW, et al., Rasch analysis supports the use of the depression, anxiety, and stress scales to measure mood in groups but not in individuals with chronic low back pain. J. Clin. Epidem.2011;1-10.

[4] Ricardo B, Amy K and Rohit L. Stress at Work-A report prepared for The Work Foundation's Principal Partners. Available http://www.theworkfoundation.com/downloadpublication/re port/69_69_stress_at_work.pdf.

[5] Sanjiv KB, Rahul S and Saini NK. Depression, anxiety and stress among adolescent students belonging to affluent families: A School-based Study. Indian J. Pediatr.2010;77(2):161-165.

[6] Ramesh N, Varsha C, Kusum N and Ram N. Depression, Anxiety and Stress Reduction in Medical Education: Humor as an Intervention. Online J. Health Allied Scs. 2011;10(1):7.

[7] Zuckerman M and Gagne M. The COPE revised: Proposing a 5-factor model of coping strategies. J. Res. Personality. 2003;37:169-204.

[8] Yi-Hsuan H, Chiao-Ying H, Chia-Yih L and Tsan-Lung H. The levels of stress and depression among interns and clerks in three medical centers in Taiwan: A cross 315 sectional Study. Chang Gung Med. J. 2011;34(3):278-284.

[9] Mark HR, Cathryn C, Rana F and Jean E. Quality of life impairment in depressive and anxiety disorders. Am. J. Psychiatry. 2005;162(6):1171-1178.

[10] Oddgeir F, Monica M, Sabine K, Karl TO and Jan HR. Comorbidity of Personality Disorders in Anxiety Disorders: A Meta-Analysis of 30 Years of Research. Available from: http://munin.uit.no/bitstream/handle/10037/4559/article.pdf? sequence $=3$

\section{Biography}

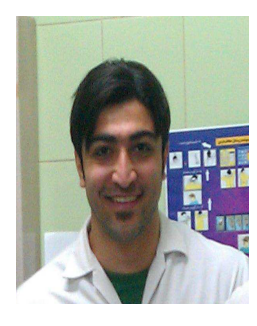

Morteza Alibakhshi Kenari was born on March 1989 at Iran, Mazandaran, Babolsar. He received the B.S. and M.S. degrees from the Sari University of Medical Sciences and Health Services at Iran, on February 2012, and he is now a Ph.D student at martyr Beheshti University, School of Medical Sciences and Health Services, Tehran, Iran. His interesting research areas include education, nursing, students sleep, sleep quality index (PSQI), anxiety, stress, learning, children studies. $\mathrm{He}$ is currently working in the field of Evidence Base Nursing. 